\title{
Evaluation of Processing Variables in Polymer Projection Sintering
}

Justin Nussbaum

University of South Florida, Tampa

Nathan B. Crane

Brigham Young University - Provo, nbcrane@byu.edu

Follow this and additional works at: https://scholarsarchive.byu.edu/facpub

Part of the Other Mechanical Engineering Commons

\section{Original Publication Citation}

Justin Nussbaum and N. B. Crane, "Evaluation of Processing Variables in Polymer Projection Sintering”, Rapid Prototyping Journal, https://doi.org/10.1108/RPJ-04-2017-0070, V 24, n 5, p880-885, 2018.

\section{BYU ScholarsArchive Citation}

Nussbaum, Justin and Crane, Nathan B., "Evaluation of Processing Variables in Polymer Projection Sintering" (2018). Faculty Publications. 5351.

https://scholarsarchive.byu.edu/facpub/5351

This Peer-Reviewed Article is brought to you for free and open access by BYU ScholarsArchive. It has been accepted for inclusion in Faculty Publications by an authorized administrator of BYU ScholarsArchive. For more information, please contact ellen_amatangelo@byu.edu. 


\title{
EVALUATION OF PROCESSING VARIABLES IN POLYMER PROJECTION SINTERING
}

\begin{abstract}
Purpose - Projection sintering, a system for selectively sintering large areas of polymer powder simultaneously with a high power projector is introduced. The paper evaluates the suitability of laser sintering process parameters for projection sintering as it uses substantially lower intensities, longer exposure times, and larger areas than conventional laser sintering (LS).

Design/methodology/approach - The tradeoffs in sintering outcomes are evaluated by creating single layer components with varied exposure times and optical intensities. Some of these components were cross-sectioned and evaluated for degree of densification while the single layer thickness and the maximum tensile force was measured for the rest.

Findings - Shorter exposure times and higher intensities can create thicker and therefore stronger parts than when equal energy is applied over longer exposures. This is different from laser sintering in which energy input (Andrew's Number) is accepted as a reliable process variable. This difference is likely because significant thermal energy is lost from the sintering region during the exposure time-resulting in reduced peak temperatures. These thermal losses can be offset by imparting additional energy through increased exposure time or light intensity.

Practical implications - Most methods for evaluating LS process parameters, such as the energy melt ratio and Andrew's Number, estimate energy input from basic process parameters. These methods don't account for thermal losses and assumes the powder absorbs all incident light. These methods become increasingly inaccurate for projection sintering with visible light where exposure times are much higher $(>1 \mathrm{~s})$ and a larger portion of the light is reflected from the power's surface. Understanding the appropriate sintering criteria is critical for the development of longexposure sintering.

Originality/value - A new method of selectively sintering large areas is introduced that could sinter a wider variety of materials by enabling longer sintering times and may increase productivity relative to LS. This work shows that new processing parameters are required for projection sintering as traditional LS process parameters are inadequate.
\end{abstract}

Keywords 3D printing, rapid prototyping, large area sintering, projection sintering, Polyamide 12 (PA12), polymer sintering

Paper type Research Paper 


\section{INTRODUCTION}

Additive manufacturing (AM) is a rapidly growing technology that enables fabrication of components directly from digital models without part-specific tooling. Many industries are adapting AM into their manufacturing processes because it is able to quickly create complex and functional components. Laser sintering (LS) is an AM method that produces high quality parts suitable for end-use (Drummera et al., 2015, Gibson et al., 2015). In LS, a focused laser scans across a preheated powder bed to locally fuse particles. A new layer of powder is then deposited on top of the first, and the process repeats as shown in Figure 1. Partially crystalline polymers with a well-defined melting point typically perform best because the powder bed can be heated near the melting point so that relatively little energy input is required to melt them (S Rüsenberg, 2012, Greco and Maffezzoli, 2003). Part distortion is reduced if the material has a small crystallization shrinkage and/or a large gap exists between the recrystallization and melting temperatures (Goodridge et al., 2012). While LS has been demonstrated with a wide range of materials (Goodridge et al., 2012), the vast majority of all polymer LS components are produced with polyamide 12 (PA12) because it best meets these stringent constraints (Tiwari et al., 2015).

LS systems are typically composed of a laser, a galvanometer for steering the laser, and a powder spreading system contained within an inert environment (Gibson et al., 2015). In order to produce parts economically with high spatial resolution, commercial systems generally have a small laser diameter $(\sim 0.5 \mathrm{~mm})$ with high scanning speeds $(\sim 1-5 \mathrm{~m} / \mathrm{s})$ (Launhardt et al., 2016, Akande et al., 2016, Peyre et al., 2015) and high optical intensities $\left(900-4,500 \mathrm{~W} / \mathrm{cm}^{2}\right)$ (Pilipović et al., 2016, Barlow, 1992). A single area is typically exposed for micro to milliseconds at a time (Akande et al., 2016, Peyre et al., 2015, Launhardt et al., 2016). During the brief exposure, high local temperatures are generated which can degrade the polymers. Area-based patterning could provide an alternative for economical processing of materials while providing longer exposure times at each location. Longer exposure times could be beneficial by limiting the peak temperature which will decrease degradation effects, providing additional time to ease the use of closed loop

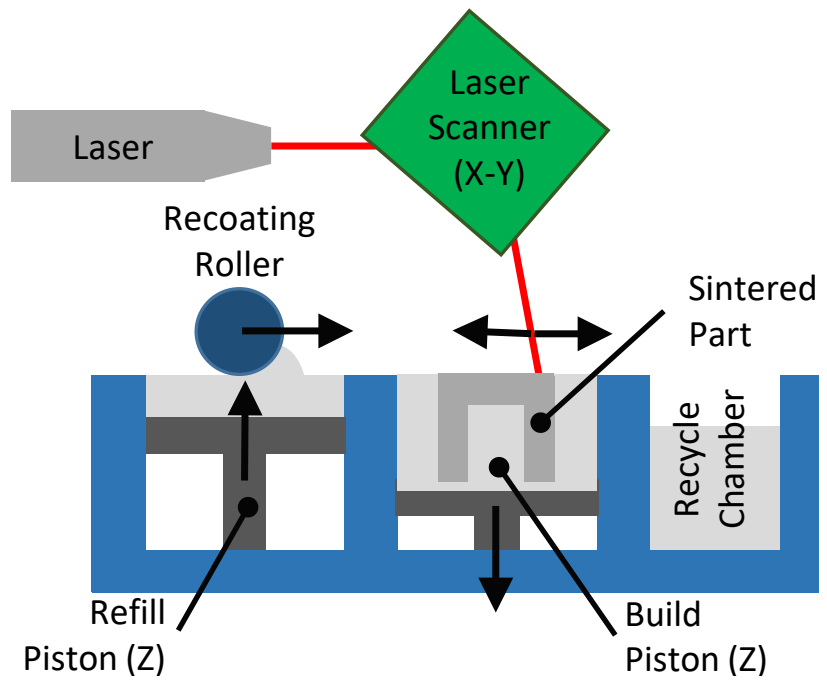

Figure 1 - During the LS process, a laser and laser scanner sinters the powder in the X-Y axis while the recoating roller and refill piston supplies powder for a new layer. 
process control, and by providing a longer time period for the polymer particles to sinter and densify.

Polymer sintering typically occurs through a time and temperature dependent viscous sintering process. This two-stage process starts with particle coalescence, followed by pore shrinkage and removal. The early stages are described by a simple viscous sintering model developed by Frenkel as seen below in Equation 1 (Frenkel, 1945, Haworth et al., 2013):

$$
\left(\frac{a}{R}\right)^{2}=\frac{3}{2}\left(\frac{\gamma t}{R \eta_{0}}\right)
$$

Equation 1

where $a$ is the radius of the growing neck between two spherical particles of radius $R, \gamma$ is the particle's surface energy, $\eta_{0}$ is the zero-shear viscosity, and $t$ is time. Liquid phase sintering is driven by the minimization of surface tension forces through reduction of the surface area (Greco and Maffezzoli, 2003). The zero-shear viscosity decreases with increasing temperature-reducing the required sintering time. In order to fully fuse and coalesce these particles, the polymer must have sufficiently low viscosity to allow the material to flow before cooling (Bellehumeur et al., 1996). Low strength components with high porosity will result if viscosities are too high or if heating times are too short. Prior polymer sintering work has focused on point processing with a scanning laser. This work addresses criteria for densification of polymer powders with longer exposures and larger areas to cure an entire layer simultaneously.

\section{EXPERIMENTAL SETUP FOR PROJECTION SINTERING}

A system was designed which enabled sintering of large areas with relatively low intensities and longer than typical exposure times when compared to LS. A schematic of the test system is presented in Figure 2. In this system, an Optoma X316 projector was modified to decrease the exposure area from a maximum of $278,709 \mathrm{~cm}^{2}$ to $3.7 \mathrm{~cm}^{2}$ giving a $20 \mu \mathrm{m}$ pixel resolution on the powder bed. Decreasing exposure area concentrated and increased the intensity of the projected image. Additionally, the optical power was boosted from $1.8 \mathrm{~W}$ to $7.3 \mathrm{~W}$, as measured from a fully white projected image on a Thorlabs S310C thermal power sensor. This sensor measures the heat energy of the input light with a flat absorption spectra from the visible to beyond $7 \mu \mathrm{m}$. Overall, this provides an intensity increase from $6.5 \times 10^{-6} \mathrm{~W} / \mathrm{cm}^{2}$ to $2 \mathrm{~W} / \mathrm{cm}^{2}$. This makes the modified projector an effective area-based heating tool with high thermal contrast. An example of a part created with this system and a thermal image demonstrating the high thermal contrast can be seen in Figure 3. The projector's optical power is provided by a $190 \mathrm{~W}$ ultra-high pressure mercury vapor (UHP) bulb. UHP bulbs produce a broad spectrum of light that ranges from the ultra violet (UV) to infrared (IR) spectrum, though a majority of the energy is contained within the visible spectrum $(400-700 \mathrm{~nm})$ and produces a mostly white light. The projector's optics and lamp are optimized to transmit light in the visible spectrum, filtering out the UV and IR light. Because of the poor transmission and high absorbance of UV and IR light in the projectors optics, it is assumed a negligible amount of these wavelengths remain in the projected image. 


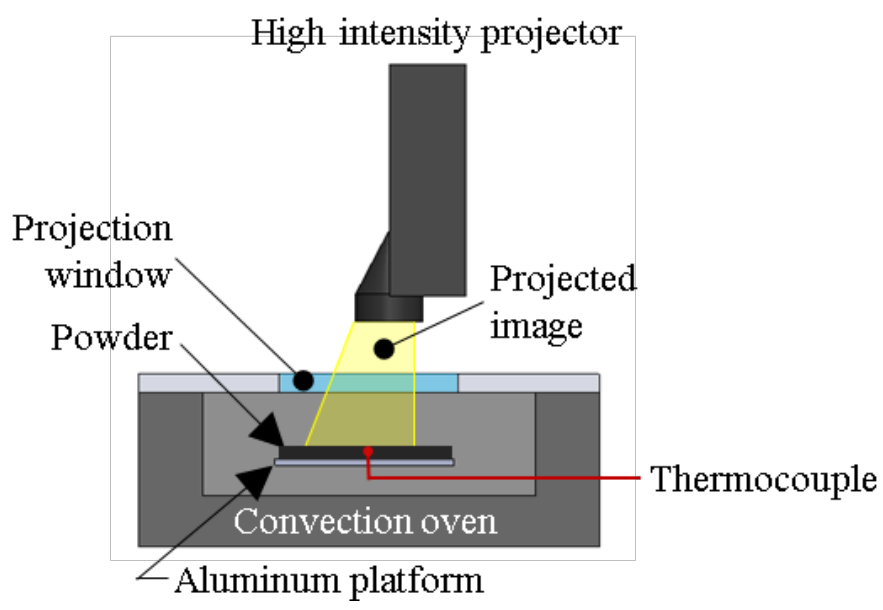

Figure 2 - In this experimental setup, an aluminum plate holds a $1.5 \mathrm{~mm}$ layer of PA12 powder at a uniform temperature. A high power projector applies patterned light to sinter the powder through a borosilicate window.

A PA12 powder layer $1.5 \mathrm{~mm}$ thick was spread onto an aluminum platform using a blade. Similar to LS, PA12 powder was preheated to $170^{\circ} \mathrm{C}$ as measured by a thermocouple placed in the center of the platform approximately $0.75 \mathrm{~mm}$ below the surface of the powder. The test platform was placed $5 \mathrm{~cm}$ from a transparent window in a modified convection oven. The convection oven provided even heating from all directions through convection rather than through conductive and radiative heaters as is commonly used in laser sintering systems. As white powders absorb only a small portion of the incident optical energy in visible wavelengths, a black PA12 powder (PA2202 provided by EOS), was utilized to maximize the energy absorbed by the powder. The PA2202 is manufactured for the AM industry and is commonly used in LS systems to create black components. 

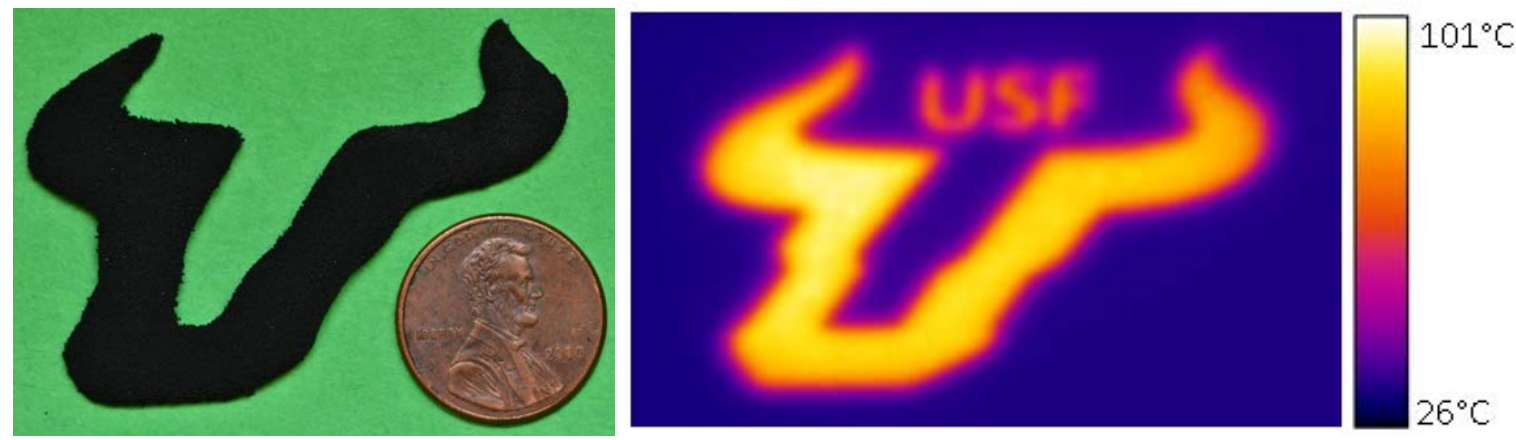

Figure 3 - left) example part created with a single, large area exposure, right) example thermal image of the University of South Florida logo on a PA12 powder bed created with the projection sintering system.

\section{ANALYSIS OF SINGLE LAYER PARTS}

\section{Degree of Densification}

To analyze the degree of densification and layer thickness, four test coupons were sintered under varying degrees of exposure time at the maximum optical intensity of $2 \mathrm{~W} / \mathrm{cm}^{2}$. After cooling, the parts were removed from the unsintered powder. They were cooled in liquid nitrogen and broken to create a brittle fracture with a nearly flat fracture surface. These components were then sputter coated with gold-palladium to create a conductive surface and imaged with a Hitachi S800 scanning electron microscope as seen below in Figure 4.
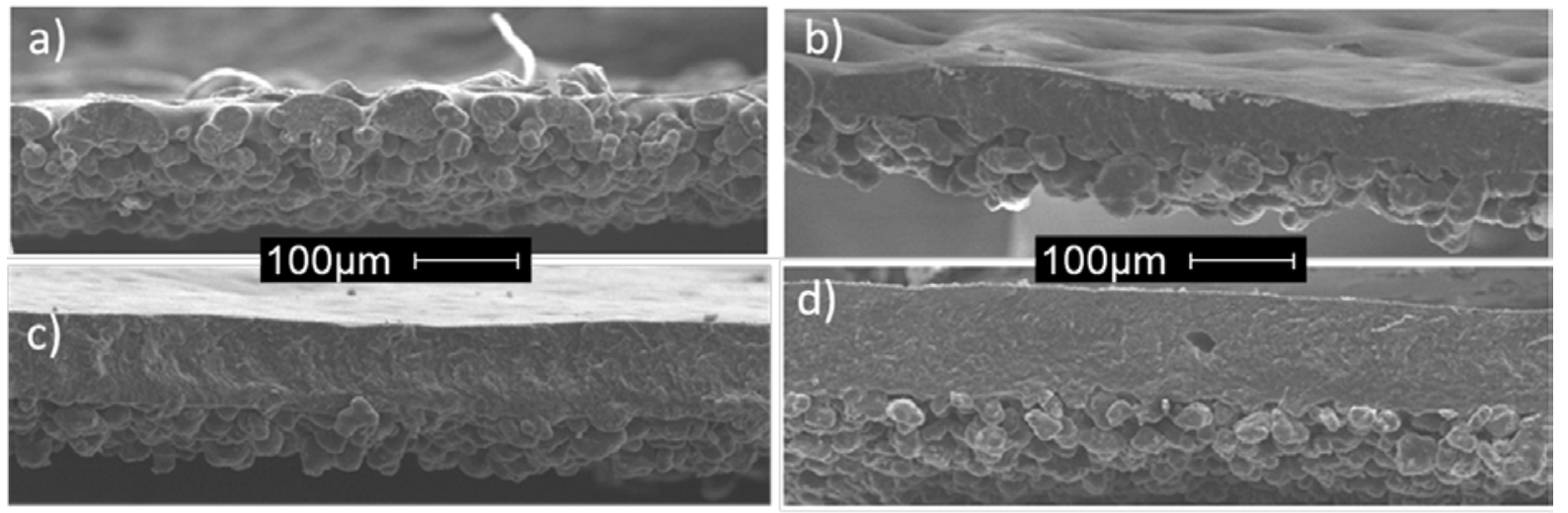

Figure 4 - All components were sintered with $2 \mathrm{~W} / \mathrm{cm}^{2}$ and are shown at 100x magnification. The exposed surface is on top in all images. a) $1.5 \mathrm{~s}$ exposure b) $1.75 \mathrm{~s}$ exposure c) $2.0 \mathrm{~s}$ exposure d) $3.0 \mathrm{~s}$ exposure.

Exposure times below 1.5 s produced parts that were too weak to be handled and therefore, were not imaged. As seen in Figure 4a, short exposure times produced limited particle necking with individual particles clearly visible through the entire part thickness. This resulted in a low degree of densification and low strength. The bottom surface shows little evidence of sintering even though the parts were lightly brushed to remove any loose powder before imaging. As the exposure time is increased, a continuous dense layer is formed (Figure 4b) which increases in 
thickness as exposure times increase (Figure 4c,d). The exposed top surface becomes smoother as well. Oliveira Setti et al. (Setti et al., 2014) has shown that a smooth surface finish represents a high density and tensile strength, indicating good particle coalescence and therefore, good sintering quality. After $3.0 \mathrm{~s}$ the fully dense layer is approximately $100 \mu \mathrm{m}$ thick. This is encouraging for the formation of multilayer parts as this is the standard layer thickness in LS and many other AM processes. A highly dense layer is a fundamental necessity and quality indicator for high component strength.

\section{Component Strength}

In order to effectively analyze the impact of exposure time and intensity, single layer tensile test specimens were created using a single exposure. The components were tested in accordance to ASTM standard D638-10. The tensile specimen geometry used in this study is similar to the standard. However, it was scaled down to fit within the maximum projected image size and the gauge width was increased to increase the maximum achievable force for ease of measurement by the force sensor. The specimen had an overall length of $23.0 \mathrm{~mm}$, a gauge length of $8.0 \mathrm{~mm}$, a gauge width of $4.6 \mathrm{~mm}$, a grip length of $4.2 \mathrm{~mm}$, a grip width of $6.6 \mathrm{~mm}$ and a transition radius of $2 \mathrm{~mm}$. After removal from the powder bed, the back of each specimen was lightly brushed then cleaned with compressed air to remove loose non-load bearing powder. The specimen thickness was measured with a dial micrometer whose contact tip was replaced with a blunted needle. The blunt needle contact tip was used to facilitate measurement of curled samples. The specimens were measured on the long axis centerline at three locations and averaged. Tensile testing was conducted on a MTS 810 hydraulic tensile testing machine.

During these tests, the components that were sintered at low energy densities (short exposure time or low intensity) showed a low degree of sintering and remained flat but were also of insufficient strength to be handled. The specimens that were well sintered exhibited some degree of curling at the edges directly after exposure in the powder bed. This made it difficult to measure the cross-sectional width in the gauge length. The forces recorded during tensile testing could not be converted to stress values because of this. Since forces do not demonstrate a material property, they are used here only for relative comparison.

Multiple methods exist for parameterizing and evaluating sintering conditions in LS that are successful in accurately predicting sintering outcomes during the short exposure times in LS. For example, Andrew's Number is cited extensively and relates various processing parameters to the overall energy input into the powder (Vasquez et al., 2011, Schultz, 2003). Another effective parameter is the energy melt ratio, which is a comparison of the amount of energy input into a specific volume of powder divided by the actual amount of energy required to melt that volume of powder (Starr et al., 2011). Both methods would predict that process performance would be independent of exposure time/intensity as long as total energy input remains constant.

To see if this holds true in projection sintering, a constant energy density was maintained by increasing exposure time as the light intensity was decreased. Three different energy density values were chosen for testing, 4.0,6.0, and $8.0 \mathrm{~J} / \mathrm{cm}^{2}$ representing a low, medium and high amount of energy input for projection sintering. 
Figure 5 shows that process outcomes clearly vary with exposure time for constant energy input. Increasing exposure time and decreasing intensity creates weaker parts. While they had less warping, the load carrying capacity is also reduced as shown in Figure 6. It is evident from the pictures shown in Figure 5 that when holding input energy constant, less sintering occurred in the parts that were exposed for a longer period of time at a lower intensity. The specimens with 4.0 $\mathrm{J} / \mathrm{cm}^{2}$ energy input had a very rough surface finish, were very weak, and showed significant variation due to the difficulty of handling the weak specimens. At higher energy inputs $\left(6 \mathrm{~J} / \mathrm{cm}^{2}\right.$, $8 \mathrm{~J} / \mathrm{cm}^{2}$ ), both thickness and strength varied significantly with changes in optical intensity, even though the overall energy input remained constant. This shows that energy input alone is not a sufficient metric for characterizing the process. At each optical intensity, both strength and part thickness also increased with energy input. As seen in Figure 6, the lower strength when using a lower optical intensity (longer exposure time) is attributed to losing more energy to the
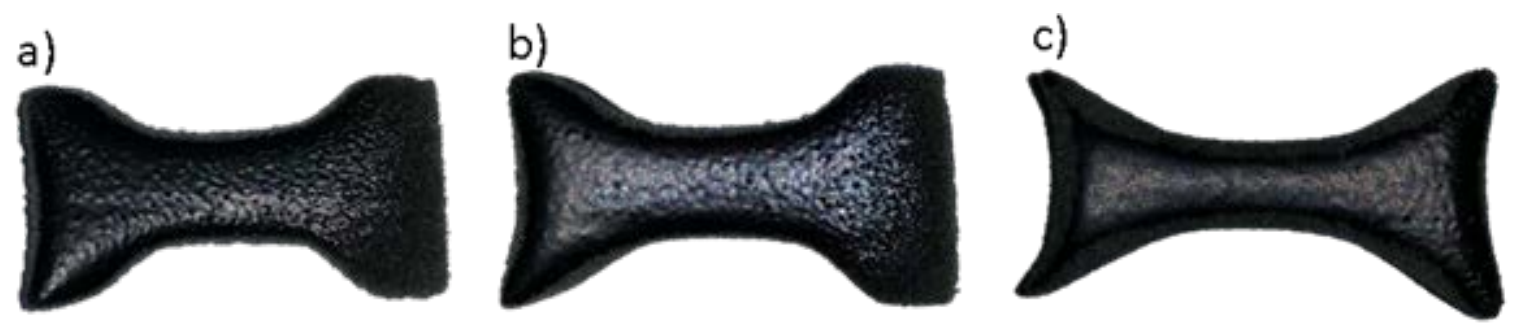

Figure 5 - Tensile specimens made with the same energy density $\left(4.0 \mathrm{~J} / \mathrm{cm}^{2}\right)$, a) 4.0 s of exposure time with $1.0 \mathrm{~W} / \mathrm{cm}^{2}$ power density, b) $3.33 \mathrm{~s}$ of exposure time with $1.2 \mathrm{~W} / \mathrm{cm}^{2}$ power density, c) $2.0 \mathrm{~s}$ of exposure time with $2.0 \mathrm{~W} / \mathrm{cm}^{2}$ power density. The degree of sintering is decreased as exposure time increases as evident by the rougher surface finish.

surrounding powder and the environment when it is input over a longer time-decreasing the peak temperature and increasing the viscosity during sintering.

The traditional LS process parameters (Andrew’s number, energy melt ratio) assume all input energy is absorbed into the powder and used in the melting process. Short exposure times ( $<1 \mathrm{~ms}$ is typical in LS) using long wavelengths $(10.6 \mu \mathrm{m}$ is typical) where the powder heavily absorbs the light, provides little time to allow for thermal losses during the heating process. Recently, Drummera, et al. (Drummera, 2015) studied this effect and evaluated exposure times from 0.06 to $0.77 \mathrm{~ms}$. While this is significantly faster than with projection sintering, they revealed a similar trend that higher part densities occur with both higher heating rates (short exposure) or additional energy input. However, this work shows that longer exposure times with lower intensities can create parts of considerable strength but require additional energy to be input. More studies are necessary to understand the limits of these tradeoffs.

Projection sintering samples with greater than 4.0 seconds of heating and energy densities of $4.0 \mathrm{~J} / \mathrm{cm}^{2}$ were too weak to be handled because excessive thermal losses prevented the powder from fully melting. Energy densities of $8 \mathrm{~J} / \mathrm{cm}^{2}$ failed to produce parts with consistent strength when spread over long time periods (low intensity). There is a clear time dependence seen as a variation in force and thickness with optical intensity. This varies from literature values for LS where the Andrew's Number necessary to produce high strength dense parts with PA12 vary from 2 to $3.5 \mathrm{~J} / \mathrm{cm}^{2}$ (Vasquez et al., 2011, Beal et al., 2009, S. Negi, 2014). This difference in energy 
input is attributed to the reduced absorptivity of the powder to the projector's visible light and the increased thermal losses which occurs during heating over longer times.

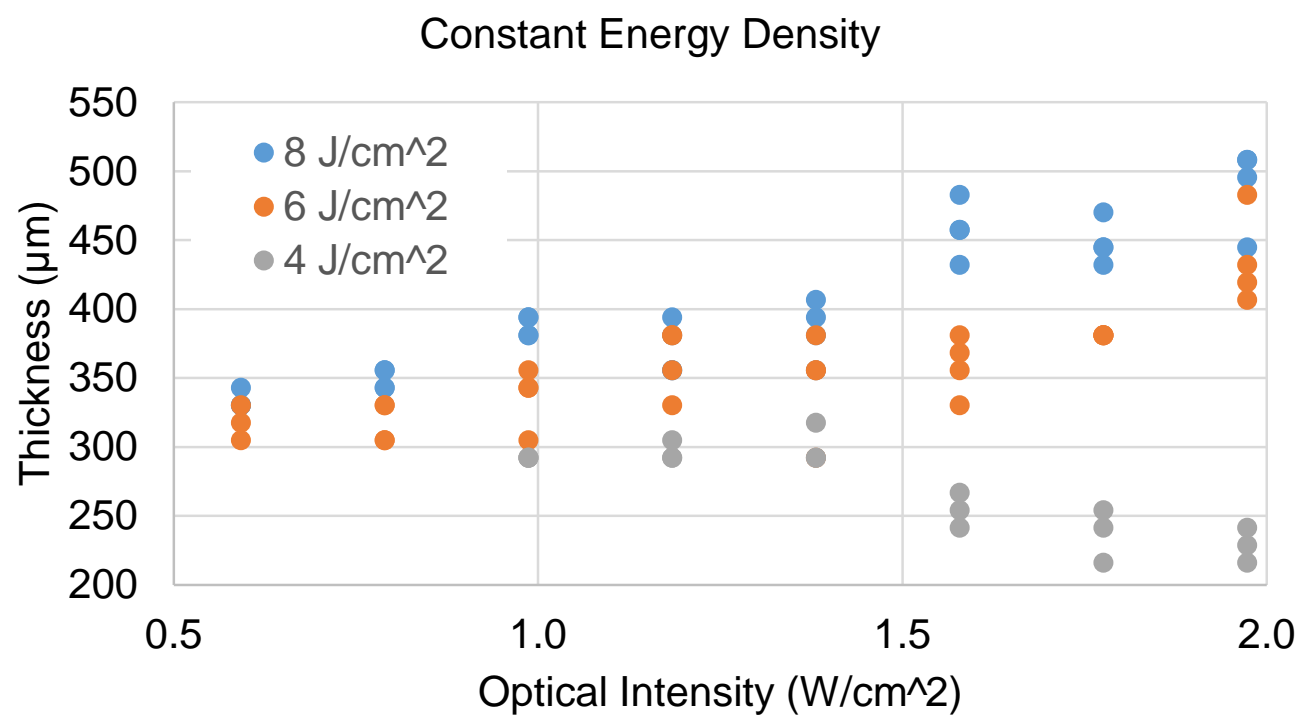

Constant Energy Density

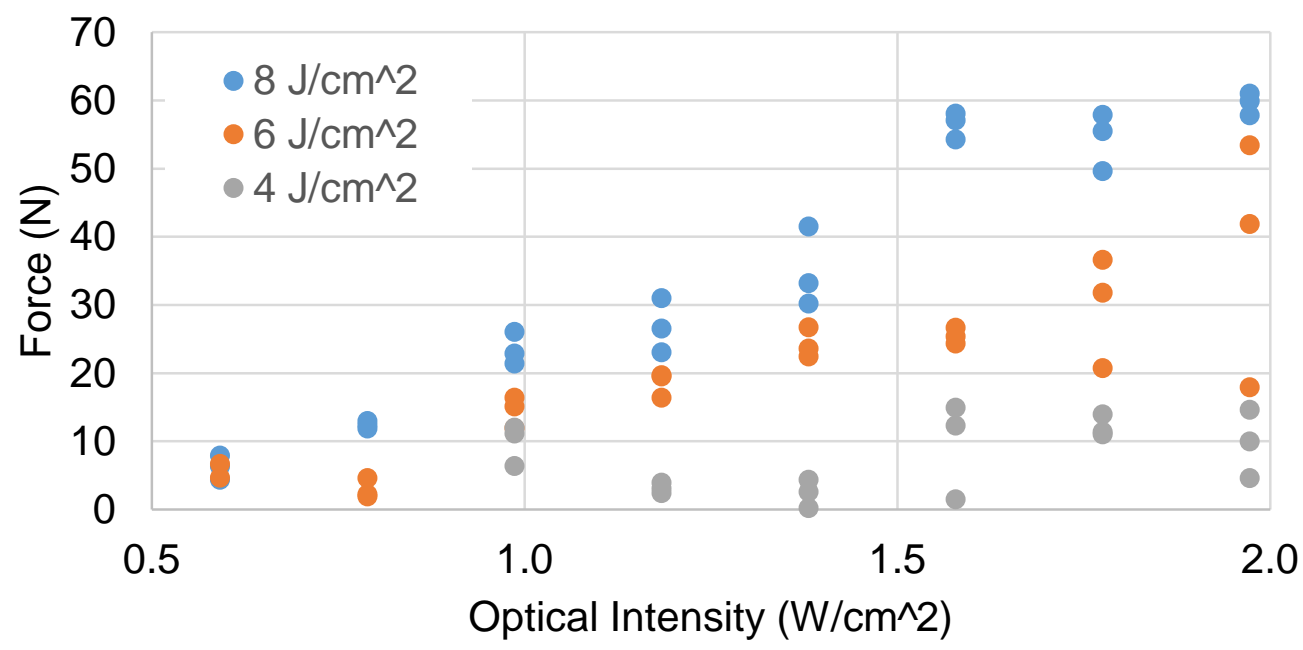

Figure 6 - Testing conditions and results for the tensile bars created with a constant energy density at three different values.

The fraction of the projected energy absorbed by the powder was estimated by comparing the intensity of reflected light on white and black PA12 powders sold for LS to establish an upper bound on reflectivity of the black powder (20\%). These results were combined with measurements of the projected intensity before and after passing through PA2202 powder of varied thicknesses. These tests show that $45-65 \%$ of the light is absorbed in the first $100 \mu \mathrm{m}$ and $75-95 \%$ in the first $200 \mu \mathrm{m}$. Thus, most of the light is absorbed, but it penetrates more deeply than highly absorbing wavelengths used in a typical $\mathrm{CO}_{2}$ system. This deeper penetration may explain why energy inputs $\left(4.0 \mathrm{~J} / \mathrm{cm}^{2}\right)$ that are typical in LS are insufficient to create adequate strength in our tests. The strong dependence of thickness and strength on projection intensity under constant energy input confirms 
that there is also a time effect. The longer exposure times that are required at low intensities allow more time for energy to be dissipated-reducing the peak temperature of the powder.

In order to create components with equal degrees of sintering, as would be indicated by equal values of part thickness and breaking force, the energy density must increase as exposure time increases to make up for the lost thermal energy. However, predicting the energy input required for different exposure times in order to achieve a constant material output is based on thermal losses and would be a function of geometry, powder, bed position, and environmental variables. Additional research is needed to develop an appropriate process control criteria for long heating times to assure consistent part outcomes. One possible approach would be to track and control the temperature at the bed's surface.

\section{CONCLUSION}

A new area-based sintering technology is used to analyze the role of exposure time and optical intensity in polymer sintering. This system is capable of sintering entire 2D cross-sections with a single exposure. This work evaluated single layer PA12 components to understand the interaction between the PA12 powder and visible light absorption. The single layer parts evaluated in this study could act as the foundation for future 3D parts. They also show that with projection sintering, layer thickness can be controlled and layers much thicker than the industry standard of $100 \mu \mathrm{m}$ can be produced. Components created with this system show that increased light intensity or exposure time increases the degree of sintering but part properties are not directly proportional to the energy input as assumed in LS. With the longer exposure times typical with projection sintering, thermal losses can become significant and must be accounted for. Common evaluation methods that do not account for losses fail to predict sintering outcomes. Development of new process parameters is critical in the development of long exposure polymer sintering processes.

Projection sintering can potentially expand the range of materials that can be sintered by permitting more control over the peak temperature and sintering time. This approach expands the understanding of sintering kinetics outside the realm of high heating rates observed in LS processes. Large area exposure could increase processing rates, but many obstacles exist including overcoming warping due to sintering shrinkage and correction of a nonuniform distribution of light across the exposure field. Future work will evaluate the effect long exposures have on the minimum feature size that can be obtained with this technology.

\section{ACKNOWLEDGEMENTS}

This work is funded in part through the National Science Foundation through CMMI 1563037. 


\section{REFERENCES}

AKANDE, S. O., DALGARNO, K. W., MUNGUIA, J. \& PALLARI, J. 2016. Assessment of tests for use in process and quality control systems for selective laser sintering of polyamide powders. Journal of Materials Processing Technology, 229, 549-561.

BARLOW, J. C. N. A. J. W. Relating Operating Parameters between SLS Machines which have Different Scanner Geometries and Laser Spot Sizes. Solid Freeform Fabrication Symposium, 1992 Austin, Texas.

BEAL, V. E., PAGGI, R. A., SALMORIA, G. V. \& LAGO, A. 2009. Statistical evaluation of laser energy density effect on mechanical properties of polyamide parts manufactured by selective laser sintering. Journal of applied polymer science.

BELLEHUMEUR, C. T., BISARIA, M. K. \& VLACHOPOULOS, J. 1996. An experimental study and model assessment of polymer sintering. Polymer Engineering \& Science, 36, 2198-2207.

DRUMMERA, D., DREXLER, M. \& WUDY, K. 2015. Derivation of heating rate dependent exposure strategies for the selective laser melting of thermoplastic polymers. AIP Conference Proceedings, 1664.

FRENKEL, J. 1945. Viscous flow of crystalline bodies under the action of surface tension. Journal of Physics, 12, 385-431.

GIBSON, I., ROSEN, D. \& STUCKER, B. 2015. Additive manufacturing technologies : 3D printing, rapid prototyping, and direct digital manufacturing, New York, NY : Springer, 2015.

GOODRIDGE, R. D., TUCK, C. J. \& HAGUE, R. J. M. 2012. Laser sintering of polyamides and other polymers. Progress in Materials Science, 57, 229-267.

GRECO, A. \& MAFFEZZOLI, A. 2003. Polymer melting and polymer powder sintering by thermal analysis. Journal of Thermal Analysis \& Calorimetry, 72, 1167-1174.

HAWORTH, B., HOPKINSON, N., HITT, D. \& ZHONG, X. 2013. Shear viscosity measurements on Polyamide-12 polymers for laser sintering. Rapid Prototyping Journal, 19, 28.

LAUNHARDT, M., WÖRZ, A., LODERER, A., LAUMER, T., DRUMMERA, D., HAUSOTTE, T. \& SCHMIDT, M. 2016. Detecting surface roughness on SLS parts with various measuring techniques. Polymer Testing, 53, 217-226.

PEYRE, P., ROUCHAUSSE, Y., DEFAUCHY, D. \& RÉGNIER, G. 2015. Experimental and numerical analysis of the selective laser sintering (SLS) of PA12 and PEKK semicrystalline polymers. Journal of Materials Processing Tech., 225, 326-336.

PILIPOVIĆ, A., VALENTAN, B. \& ŠERCER, M. 2016. Influence of SLS processing parameters according to the new mathematical model on flexural properties. Rapid Prototyping Journal, 22, 258.

S RÜSENBERG, R. W., F. KNOOP, H.-J. SCHMID, M. GESSLER, H. PFISTERER. Controlling the Quality of Laser Sintered Parts Along the Process Chain. Solid Free Form Symposium 2012 Austin, Texas.

S. NEGI, S. D., , R. SHARMA. Influence of Process Parameters on Mechanical Properties of Parts Fabricated by Selective Laser Sintering International Conference on Additive Manufacturing Technologies, 2014 Bangalore. 
SCHULTZ, J. P. 2003. Modeling Heat Transfer and Densification during Laser Sintering of Viscoelastic Polymers. Doctor of Philosophy, Virginia Polytechnic Institute and State University.

SETTI, G. D. O., SILVA, J. V. L. D., OLIVEIRA, M. F. D., MAIA, I. A., JESUS, D. P. D., SAVU, R., SANTOS, T. E. D. A., SOUZA, R. D. C. Z. D. \& JOANNI, E. 2014. Surface methods for monitoring the densification of parts in the selective laser sintering process. Rapid Prototyping Journal, 20, 157-163.

STARR, T. L., GORNET, T. J. \& USHER, J. S. 2011. The effect of process conditions on mechanical properties of laser-sintered nylon. Rapid Prototyping Journal, 17, 418-423.

TIWARI, S. K., PANDE, S., AGRAWAL, S. \& BOBADE, S. M. 2015. Selection of selective laser sintering materials for different applications. Rapid Prototyping Journal, 21, 630.

VASQUEZ, M., HAWORTH, B. \& HOPKINSON, N. 2011. Optimum sintering region for laser sintered nylon-12. Proceedings of the Institution of Mechanical Engineers, Part B: Journal of Engineering Manufacture, 225, 2240-2248. 